\title{
Urdimento
}

Revista de Estudos em Artes Cênicas

E-ISSN: 2358.6958

\section{Mi relación con la tecnología no es una relación solemne: Entrevista a Matías Umpierrez}

Entrevista com Matías Umpierrez concedida à Mariana Lima Muniz

\section{Para citar este artigo:}

UMPIERREZ, Matías. Mi relación con la tecnología no es una relación solemne: Entrevista a Matías Umpierrez. Entrevista concedida à Mariana Lima Muniz. Urdimento, Florianópolis, v. 2, n. 38, ago./set. 2020.

DOI: httpdx.doi.org/10.5965/14145731023820200050 
Mi relación con la tecnología no es una relación solemne: Entrevista a Matías Umpierrez

Matías Umpierrez entrevista concedida à Mariana Lima Muniz ${ }^{1}$

\title{
Resumen
}

Matías Umpierrez es un artista multidisciplinario nascido en Argentina, en el inicio de los anos 1980, de padres uruguayos, que produce obras que dialogan con el teatro, el cine y las artes visuales. En esta entrevista, discute su trabajo en diversos países en proyectos que integran tecnologías de la información con el cotidiano de las personas de las grandes ciudades.

Palabras-clave: Teatro. Tecnología. Lenguaje híbrido.

My relationship with technology is not a solemn relationship: interview with Matías Umpierrez

\begin{abstract}
Matías Umpierrez is a multidisciplinary artist born in Argentina in the early 1980s, of Uruguayan parents, who produces works that dialogue with theater, cinema and the visual arts. In this interview, he discusses about his works in several countries around the world on projects that integrate information technologies with the daily lives of people in large cities.
\end{abstract}

Keywords: Theater. Technology. Hybrid language.

1 Pesquisadora do Programa Pesquisador Mineiro FAPEMIG. Professora Titular do Departamento de Artes Cênicas, atuando na Pós-graduação em Artes e Curso de Graduação em Teatro da Escola de Belas Artes/UFMG. Pós-Doutorado na Universidad de Buenos Aires com Jorge Dubatti, bolsa Estágio Sênior da CAPES. Essa entrevista é resultado de pesquisa apoiada pela FAPEMIG e pela CAPES. marianamuniz32@gmail.com 


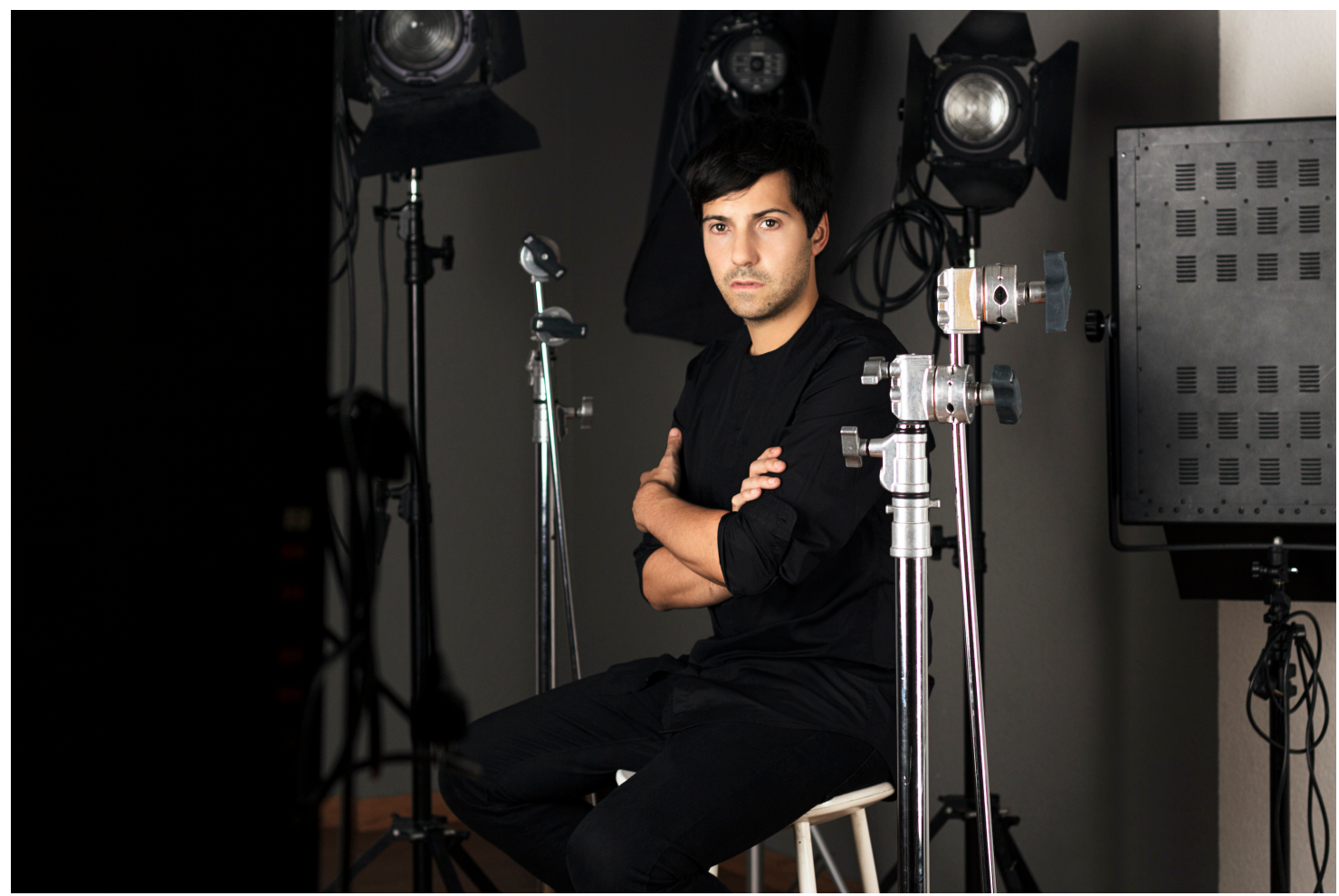

Matías Umpierrez é um ator e um artista multidisciplinar argentino, nascido em Buenos Aires em 1980, que produz obras que dialogam com o teatro, o cinema e as artes visuais. Trabalha em diversos países do mundo em projetos que integram tecnologias da informação com o cotidiano das pessoas das grandes cidades. Também trabalha como curador em festivais e centros culturais. Foi contemplado com a Bolsa Rolex em 2016 e desenvolveu um trabalho junto a Robert Lepage. Seus trabalhos foram apresentados por instituições, tais como: El Cultural San Martín, Museu MALBA, MoMA (Museu de Arte Moderno), Lincoln Center, BAFICI, Pinacoteca do Estado de São Paulo, Festival de Cannes, Oficina Cultural Oswald de Andrade São Paulo, Complexo Teatral de Buenos Aires, Centro Cultural Rojas, Universidade de Buenos Aires, entre outros. Atualmente, mora em Madri. 
Te explico lo que estoy investigando para que sepas un poco de mi proyecto. Lo que hago es una investigación sobre artistas brasileños y argentinos que han quitado el actor de la escena a través de tecnologías de transmisión remota. El público se depara, entonces, con que no hay actores en presencia y qué tensiones eso provoca en el público en la crítica de teatro que no sabe si es o no teatro. Esa es una pregunta que me importa más pensar sobre ella que contestarla. Estoy haciendo esta investigación con Jorge Dubatti y él me hablo mucho de ti y sobre Distancia². Además, escribió un comentario sobre tu obra, no sé si lo conoces...

Algo me contó, pero no lo tengo yo.

Primero quisiera que me hablaras un poco del proceso de la obra, si ya empezó con la idea de hacerlo vía streamingo si eso fue una cosa que surgió durante el proceso.

Primero te cuento un poco, de manera general, qué es lo que hago yo en realidad. Soy una artística interdisciplinario que pone en juego una obra que piensa, principalmente, en cómo nos relacionamos con la ficción y por qué la ficción sigue siendo necesaria para la humanidad a través de los tiempos. A partir de ésta premisa la obra va pensando dispositivos posibles para relacionarnos con la ficción, por eso generalmente cada pieza formula un dispositivo de acceso para el público desde distintas perspectivas. Mi intención siempre es relacionar a la ficción con los mecanismos del presente; por eso aparece la virtualidad y la tecnología. Por más que nos resistamos a pensarlo, el mundo está dividido entre varias realidades, y entre ellas la realidad física y la realidad virtual. Ambas tienen incidencia en nuestro cotidiano, por eso en mi obra confluyen orgánicamente sin pretender cambiar ninguna disciplina sino poder pensar más allá del/los género(s) desde una perspectiva transdisciplinar.

Mi punto de partida es la acción del ritual y por eso el teatro siempre está presente en cierta manera. En los rituales suele haber una invocación, una figura sensible que evocamos desde nuestro presente y que viene de un "más allá" interno o externo. En mi caso esa "figura" aparece mediada por la virtualidad y, de 
la misma manera, confluye el encuentro de "cuerpos" de distintas naturalezas. Me gusta pensarlo como un encuentro sin jerarquías, donde las realidades físicas y virtuales confluyen orgánicamente casi evocando el mito de la caverna de Platón dónde nos es difícil distinguir qué cuerpo invoca a qué otro cuerpo. En esa conjunción está mi trabajo.

\section{Eres muy joven empezaste a los veinte años...}

Yo empecé con 19, en 1999 en Buenos Aires, una ciudad muy singular para el teatro por su gran producción independiente, algo similar de lo que sucede en ciudades como São Paulo. Empecé a trabajar como actor, y también como asistente de dirección, y productor y diseñador gráfico y todo lo que fuera posible en relación con el teatro. Esto justamente me dio la posibilidad de vivir económicamente de lo que hacía, justamente, formando parte de una gran cantidad de cooperativas, que es la manera como se hace teatro en Buenos Aires.

Originalmente, tomé muchas clases de teatro, trabajé con muchos maestros. La formación más atractiva, generalmente, en Buenos Aires, se da en talleres de maestros independientes. Mis maestros fueron Julio Chávez, Rubén Szuchmacher, después también estudié con actrices como Mónica Bruni o Vanesa Weimberg y fui tomando un sin número de talleres con gente que me daban ganas de pensar el cuerpo, principalmente. Pero, mientras tanto, a los 18 años debí estudiar una carrera universitaria por, casi, un mandato familiar y estudié dirección de arte en publicidad. Lo que me hizo ser muy consciente todo el tiempo de la relación con el público. La publicidad tiene todo un lugar que tiene que ver mucho con el estudio del consumidor, estudiar perfiles, maneras de relacionarse con el consumo y demás. Y yo creo que nada es casualidad en la vida, pues me parece que uno, sin querer, acaba tocando lugares que lo hacen conectar con el mundo que investiga desde otras perspectivas. Y en un momento, en medio de todas esas realidades y motivaciones, empecé a producir mis obras como director.

\section{¿En qué año?}


En el 2006, recién hace 10 años. Y ahí produje mis primeros dos trabajos en ese año. Mi primera obra se llama Novela (2006) y trata la relación de una madre que es abandonada por esposo y que la deja a cargo de sus tres hijos. Esa mujer lo único que hace, en medio de su depresión, es mirar telenovelas. En el momento que empieza la pieza de teatro que ve el público, esta madre plantea un juego con sus hijos dónde trata de revisar su vida como si fuera una telenovela. Sus hijos pasan a ser casi protagonistas de esa pieza que empieza a ser, en realidad, la vida de ella y la obra empieza a mezclar realidad y ficción hasta un punto que no sabes cuál es la historia de esta mujer y cuál es la telenovela que ella mira todas las tardes. Aunque sea mi primera obra, para mí Novela es una obra bastante central de mi trabajo, porque allí se inicia una pregunta que va atravesando mi obra posterior y que es cómo el público se relaciona con la ficción en su cotidianidad. Y, también, por otro lado, todo lo que eso conlleva. Por eso me parece hoy la tecnología un medio posible para acercarse a la ficción. También me interesa pensar cómo la ficción genera un 'encuentro' que le permite a algunas personas transitar conflictos personales, sociales, políticos y económicos. Con en el caso de la ama de casa que protagoniza Novela, el conflicto central de su vida, el abandono.

\section{Hago un paréntesis... Entonces, para ti, ¿la tecnología es algo positivo?}

Siempre depende cómo la utilicemos, como todo en la vida. Por ejemplo, en Novela la acción dramática se ubica en la década del 50. Tomé esta época porque me interesaba el primer momento dónde la gente empezó a convivir asiduamente con la tecnología, es decir con artefactos que definían un territorio que relacionaba al espacio doméstico con el tecnológico y que en algunos casos abrían una nueva dimensión en la percepción de la realidad en el exterior. También, de alguna manera, estas nuevas tecnologías simplificaban algunas tareas diarias, y como consecuencia también las complejizaban permitiendo que emerjan nuevos estados emocionales frente a la realidad contemporánea.

A partir de eso, hice una serie de performances y me nombraron coordinador 
del área de teatro en el Centro Cultural Rojas, que depende de la UBA ${ }^{3}$. Y ahí, más allá de hacer mi obra como artista, durante siete años, generé proyectos curatoriales. No fui por las vías de un programador convencional que simplemente programa espectáculos, sino que fui generando conceptos para el desarrollo de proyectos donde artistas puedan reflexionar y complejizar distintas perspectivas de las artes performáticas. El Rojas se caracteriza históricamente por ser un centro abierto a la experimentación en la ciudad de Buenos Aires. También mi decisión con respecto a la curaduría tenía que ver con generar espacios interdisciplinarios de creación. En mi gestión en el Rojas empecé a tener nuevas perspectivas del espectador. Eso se dio por ver como se relacionaba el espectador, no sólo con mi obra como artista, sin también con la obra de otros creadores que podía acompañar como curador.

Luego de esas experiencias como curador empecé a sentir que el público había evolucionado, lo digo en relación con todo lo que había podido escuchar sobre él en mi formación. Percibí que el público, en el presente, tiene mucha menos capacidad de sometimiento frente a la obra de un artista y que el espectador, en la era digital, es un espectador interactivo que puede tener una voz frente a lo que percibe. Entonces comencé a tener una necesidad de mover mi trabajo a otra dimensión que me permita dialogar con ese público de una manera más orgánica. Inclusive porque yo me siento identificado con ese público inquieto que hoy tiene la capacidad de decodificar muchos signos al mismo tiempo. Una gran parte de la población que vive en las grandes ciudades puede estar, en su cotidiano, escribiendo un texto en Word dentro de su trabajo, posteando una foto en Facebook, escribiendo un estado en Twiter y poniendo likes en una foto en Instragram. Esto le da una capacidad mucho más macro cuando llega al teatro y está en el oscuro de la sala. Muchas veces siente que quiere tener una voz, quiere moverse, quiere poder interactuar con el intérprete. Pareciera que el espacio "sagrado" del escenario se ha profanado por un público que necesita dialogar y tomar decisiones en conjunto con el artista. Eso no significa que todo el teatro tenga que ir en esa dirección... Esa es mi posición con respecto al teatro o la

${ }^{3}$ Universidad de Buenos Aires. 
performance como creador. Sin embargo, como espectador también disfruto de las obras que siguen los ejes tradicionales de representación. Pero, en el momento de crear, como creador, me empieza a pasar otras cosas dónde empiezo a necesitar desafíos muchos más radicales en lo personal.

Para ubicar Distancia en el tiempo. En el año, 2013, produje dos proyectos. Uno se llama Distancia y el otro se llama TeatroSOLO una serie de performances que se desarrollan en sitios específicos de una ciudad para el acceso de un solo espectador a la vez. TeatroSOLO es un proyecto global que va cambiando de idiomas, actores y conflictos. Este proyecto se presentó en los últimos 3 años en 7 ciudades como Buenos Aires, São Paulo, Nueva York, Madrid, Portland, San Sebastián y Graus. Yo crecí en un sistema globalizado y mi trabajo también gira entorno a un sistema nómade que irse resinificando a partir del sistema global.

\section{$Y$ te identificas como argentino? ¿O te identificas como un ciudadano de varios países?}

Yo soy hijo de inmigrantes, a la vez tengo familiares que emigraron a otros países, por eso crecí con la sensación de extrañar personas y territorios que estaban a la distancia, y a la vez cuando me movía a esos territorios extrañaba otros territorios. Por eso siempre digo que mi vida y mi trabajo se ubican en las fronteras, las fronteras de las disciplinas, de los territorios. En realidad, la frontera es mi lugar y desde ese lugar se disparan todos mis proyectos.

Por ejemplo, en mismo año de Distancia, cree TeatroSOLO(2013) para generar un juego de opuestos. En el caso de TeatroSOLO, el principal fin es llevar al espectador hacia el origen de la representación o, lo que me gusta pensar como la primera chispa de la teatralidad, y que es justamente: la tradición oral que sucede previo a los ritos dionisíacos de la Grecia antigua (dónde se empieza a pensar la primera idea del ritual en el sentido discursivo-teatral y colectivo). Pero me interesa la tradición oral en el sentido de todas aquellas personas que transmitían mitos y leyendas para mantenerlos vivos de generación a generación. Podríamos decir que en este acto, de contar esas historias, ya existía el gesto de 
la representación. Uno de mis maestros siempre decía que un buen actor es aquel que sabe contar bien una historia. Porque en este acto, ya aparecen varias de las condiciones que encarnan a un actor en el sentido emocional y discursivo. Entonces, en TeatroSOLO, me interesaba, y me interesa, emancipar el espectador de la butaca, sacarlo del teatro o de los lugares preestablecidos para la apreciación de las artes y acercarlos a performances que solamente suceden para él, o ella, en distintos puntos de la ciudad que pueden ser desde una estación de subte de Buenos Aires, una fábrica de costura en São Paulo, un edificio abandonado en medio de Nueva York, o una iglesia ubicada en la cima de una montaña en el Pirineo español.

TeatroSOLO lo conforman cinco piezas teatrales que suceden al mismo tiempo sumergidas en cinco localizaciones en cada ciudad. El/a espectador/a compra su entrada de manera virtual. Al comprar su entrada, elige la localización que quiere ver. Cada pieza dura treinta minutos. Entonces lo que hace el/la espectador/a es seleccionar la locación, la obra que quiere ver en el horario y día que desea. Lo que hace también que el acceso a ver la pieza tenga un arco más grande, porque las obras están desde las doce del mediodía hasta las nueve de la noche.

\section{¿Uno puede hacer un recorrido y ver todas las obras?}

Si quisiera sí. Pero, en realidad tiene que elegir porque cada pieza tiene un precio por separado porque no están directamente interrelacionadas. Generalmente son piezas que te piden cierto compromiso emocional y para mi está bien ver una performance por día. Pero hay gente que ve dos y gente que ve tres. En realidad, son 5 porque siempre me interesa la idea de una totalidad excedida, en la que cada espectador tiene que recortar a partir de sus elecciones como frente al cosmos virtual. Me gusta la idea de distintos amigos, o parejas, que ven piezas distintas y que luego de la performance transmiten a aquellos que no vieron la misma pieza, por medio de la misma tradición oral, aquello que vivieron en solitario. 


\section{He leído que es un espectador único.}

Claro, si, es sólo un espectador. El/la espectador/a saca el horario que quiere ir que, por ejemplo, son 13.30 horas en el metro. Le llega a su e-mail un instructivo que le dice qué estación de metro es, en dirección a que lugar va el vagón y en qué lugar de la estación tiene que esperar. Cuando llega el día y e l/la espectador/a espera en este banco de la estación que se le indicó, a esa hora indicada algo de la realidad será atravesado por una ficción, solamente para él-ella, y no para todas las otras personas que están viajando en este metro (que ni siquiera percibirán que allí está sucediendo una performance). Entonces, e l/la espectador/a, por una decisión propia, entra en un acto performático. Y esa performance empieza a conspirar para que su realidad se vuelva completamente una ficción. La situación es que los encuentros son totalmente distintos en cada caso, en el caso del metro, por ejemplo, entre el tumulto de la gente hay un actor que en un momento te pregunta la hora y que, sin querer, empiezas a entrar en su historia y empiezas a vivir un mundo paralelo. Por poner el ejemplo de una de las piezas.

Como ya se presentó en siete ciudades del mundo, hay algunas piezas que fueron creadas para el sistema global, y otras que son creadas originalmente para la ciudad intervenida a partir de distintas problemáticas sociales. Por ejemplo, en el caso de São Paulo, uno de los barrios que intervenimos fue el Bom Retiro porque era donde se ubicaba la Oficina Cultural Oswald de Andrade que fue el principal productor del proyecto. Su director en ese momento, Celso Curi, me sugirió que desarrollemos una de las piezas en mismo barrio de la institución, entonces empezamos a investigar sobre las problemáticas que existían en ese barrio. Uno de los temas más complicados era la esclavización de trabajadores inmigrantes en las fábricas textiles. En algunos casos esos trabajadores, según lo que fuimos investigando, permanecerían encadenados hasta que pagan sus deudas. Ese mundo sumergido permanecía como un tabú frente a los otros y por eso sentí que había que hablar de ello. En TeatroSOLO el público transita conflictos que son parte de su cotidiano y que, en el medio de la voz colectiva, muchas veces no logra 
tomar una posición personal frente a ese conflicto. Por eso en esta experiencia el espectador no es un voyeur, sino que vive una experiencia donde tiene un rol activo para tomar decisiones frente a la trama y los conflictos de la escena.

En este proyecto también me interesaba reconocer cuáles son los mitos en el presente. Creo que, en las grandes ciudades, temas que tienen ver con nuestras realidades como temas que son de común conocimiento, funcionan a su vez como mitos de un saber colectivo. Por eso en TeatroSOLO los espectadores ingresan en algunos de esos mitos y los transitan por medio de la ficción.

Estrenamos TeatroSOLO por primera vez en Graus, una pequeña ciudad en los Pirineos, y después en Buenos Aires, luego se fue replicado en otras ciudades por medio de invitaciones de programadores y curadores. En muchos casos, TeatroSOLO se presenta en coproducción con una Institución de Artes Escénicas y un Museo de Arte Contemporáneo. Como por ejemplo en São Paulo con Museo Pinacoteca y Oficina Cultural Oswald de Andrade, en Madrid con el Centro Dramático Nacional y el Museo Reina Sofía, en Buenos Aires con el Complejo Teatral de Buenos Aires y Museo Malba, entre otras instituciones que lo presentaron. Me interesa esta combinación porque genera el cruce que justamente hace mi obra.

Volviendo a Distancia, en la segunda parte del año de 2013, estrené la otra pieza que es la antítesis de TeatroSOLO. Primero porque vuelve a pensar el espacio de la expectación teatral en el sentido colectivo, pero sin embargo el espacio del cuerpo del intérprete en un sentido virtual. La principal pregunta que detonó el espectáculo fue: ¿cómo el teatro tiene pensado acceder a la era virtual? Entonces, con TeatroSOLO me interesaba llegar al génesis del teatro para que el/la espectador/a sienta su cuerpo fuera del colectivo social en plena era virtual; y en Distancia acercarle al cuerpo virtual y las problemáticas de los estados de la representación en la contemporaneidad. Muchas de las personas actualmente estamos una gran parte del día en frente a la virtualidad, pero ¿qué pasa cuando vamos al teatro y nos encontramos con el cuerpo físico? Un cuerpo físico que no tiene las características dinámicas que tiene en el estado virtual. 
Entonces sentí que necesitaba dialogar con este espectador/a que estaba frente a ese conflicto y ese espectador/a que, por ende, tiene una gran capacidad de decodificar una gran cantidad de signos al mismo tiempo. La obra, por eso, sucede con cuatro actrices en vivo, en directo desde cuatro ciudades que, en muchos casos, están a más de 7.000 quilómetros de distancia. Entonces, esas cuatro actrices hablan cuatro idiomas distintos... Hablan alemán, francés, inglés y castellano. Por esta situación el público se enfrenta a una dramaturgia en 4 idiomas, y en 2 sentidos: el que escucha y el que tiene que leer por no entender alguno de los idiomas.

Otro de los temas que me interesaba indagar es el recorte que estamos obligados a hacer frente al universo virtual. Ese recorte se da porque el cosmos virtual es casi infinito (porque está todo el tiempo creciendo). A medida que crecemos nosotros, crece la población, crecen los usuarios, crece la interfaz, y pareciera que crece el éter virtual sin medida. Por esto existen herramientas como el Google que nos permiten "recortar", por medio de las búsquedas específicas, en términos reales.

Por otro lado, me interesaba amplificar el radio del escenario. No solamente en términos físicos y virtuales, sino también de información que contenga. La obra está llena de hipervínculos. Todo el tiempo se abren ventanas y ventanas, pantallas y pantallas, por eso en un momento uno puede encontrarse con ocho pantallas y, en otro momento, puede encontrarse con 30 pantallas con información simultánea.

\section{¿Este comando de abrir y cerrar pantallas es de los personajes? ¿O sea son estos personajes que van abriendo pantallas y el público ve lo que ellos ven o es un comando externo?}

En términos dramáticos es lo que las actrices van abriendo. Por ejemplo, yo estoy hablando con alguien al que quiero y le digo, "mira este video..." y le envío un link que le abre una nueva ventana en simultáneo.

También me interesaba generar otra dialéctica entre lo virtual y el teatro. Por 
ejemplo, con lo que normalmente se hace en el teatro que es amplificar música virtual y no necesariamente de músicos en vivo. Por eso en Distancia el público no se encuentra con una pantalla, sino con una gran estructura de cubos que están rodeadas de pantallas que generan distintas dimensiones. Las pantallas generan texturas, generan por momentos estados corpóreos virtuales, porque es justamente en contraste entre telas que genera ciertos cuerpos. Allí las actrices, las voces y los espacios son virtuales. Dentro de esas imágenes uno puede percibir músicos en vivo que tocan sus instrumentos para esas actrices y universos que se encuentran encriptados en la virtualidad.

Distancia es una pieza de teatro porque todo se ensambla en tiempo real frente al espectador. Cada elemento no tiene razón dramática por separado, por dentro del sistema de sincronicidades del escenario (y el tiempo real en la sala) esos elementos cobran un sentido global y por ende teatral frente al público.

\section{El proceso de la creación de la obra, ¿se desarrolló también virtualmente?}

Yo trabajo mucho desarrollando el concepto. En este sentido, trabajo mucho solo o con referentes que me interesa dialogar. Pero, cuando llego al actor/actriz, está mucho del trabajo resuelto. En Distancia, las actrices se integraron cuando ya estaba el texto traducido a cuatro idiomas. Actrices que, en un caso específico, conozco sólo virtualmente.

\section{¿Y la ensayabas por streaming?}

Sí, siempre fue por streaming. El proceso de Distancia fueron dos meses con ensayos todos los días en distintos espectros horarios con cada una de las cuatro protagonistas. En algunos momentos estaba presente todo el equipo: Rafael Sucheras quien compuso la música para la obra, Matías Fabro quien me ayudó a desarrollar el sistema virtual y Malena Juanatey quien me asistió en la dirección. Eran encuentros muy privados porque justamente los escenarios eran las casas de las mismas protagonistas. Esta fue una estrategia desde un principio porque 
me interesaba que el público se acerque a intérpretes que realmente estén en un estado muy íntimo frente a la realidad y a la mirada del otro.

Yo siento que todos los dispositivos que creo como artista son absolutamente frágiles, por eso para mí el actor/actriz siempre tiene que estar en un estado de mucha fragilidad. Por eso, en el ejemplo de TeatroSOLO, el más vulnerable no es el/la espectador/a, sino que el/la intérprete. Muchas veces, en las intervenciones urbanas, el/la performer tiene un espacio de 'poder' frente al otro/a que le mira. Y el espectador/a, casi siempre, tiene miedo a entrar en ridículo. TeatroSOLO es todo lo contrario. Son accidentes entre la realidad y la ficción que hacen necesaria la fuerza del espectador para que el/la performer pueda constituirse y para que la ficción exista. Por eso este estado de vulnerabilidad crea una intimidad muy fuerte en localizaciones que son muy dispares en el sentido de lo público y lo privado.

\section{¿En algunos momentos, cuando estabas dirigiendo Distancia, fue como dirigir cine?}

Si, pero un poco más complicado, porque en cine yo tengo la relación directa con la cámara y con el plano que quiero lograr. En Distancia, para lograr la intimidad que buscaba, necesitaba que las actrices mismas sean quienes manipularan las cámaras de sus computadoras. Así generaban distintos planos, movimientos de cámaras que iban armando la puesta en escena. Por eso en esta pieza las actrices son sus propias técnicas y realizadoras.

\section{Hay un momento que llegan a cantar juntas en unísono...}

Sí, la pieza lo que piensa es cómo una marea de cuatro mujeres que están en cuatro momentos distintos de sus vidas, se enfrentan a una relación que sucede a la distancia y que se toma de la virtualidad para que exista como tal. El punto de partida argumental de la pieza, que no tiene nada que ver en términos reales, pero sí en términos conceptuales, fue es La Voz Humana de Cocteau. Siempre quise hacer algo con esa obra. Me interesaba el gesto de Cocteau, no 
necesariamente el texto. No usé el texto, pero era un texto que a mí siempre me gustó. Investigando sobre el texto, me di cuenta de que Cocteau escribe la pieza en 1930, cuando aparece el teléfono. En realidad, no solamente es una obra que habla de una mujer que agoniza por amor frente a esa voz que está al otro lado del teléfono; sino que también habla cómo la aparición de esta nueva tecnología cambia la relación frente al discurso amoroso. A la protagonista, durante La voz humana, le cuesta distinguir por medio de la virtualidad si quien ama le dice la verdad o le miente, tomándose del ocultamiento de esta nueva dimensión física. Entonces, en Distancia, lo que me interesaba era pensar que algunas personas somos, por momentos, muy ingenuos frente a la tecnología. Recuerdo que Jorge Dubatti, durante una entrevista, me comentó que él siente que en mi obra las protagonistas padecen la ausencia de lo físico frente a lo virtual. ¿Tal vez podría ser lo mismo que podría padecer el teatro frente a la virtualidad?

\section{¿Y estás de acuerdo con Dubatti?}

Yo tengo una relación muy orgánica con la tecnología y pienso que la evolución es entender que hay nuevos paradigmas que definen distintos modos de relacionarse con el otro. Si esos nuevos paradigmas existen es por la absoluta necesidad de quienes lo crearon, es decir seres que viven hoy en este mundo.

\section{Pero la virtualidad simplifica mucho las cosas también.}

Es mucho mejor que exista y que existan más opciones entre las que uno pueda elegir. Claramente es una evolución en algunos sentidos, no creo que sea una involución. Esta nueva existencia no prohíbe a nadie enviar cartas, sino que existe una nueva posibilidad para aquellos que la quieran tomar.

Creo que estos sistemas también son nuevas herramientas para los artistas. A la vez estas nuevas formas nos abren nuevas posibilidades y también nos obligan a desarrollar nuevas metodologías a los artistas que queremos trabajar con ellas. Algunos de mis proyectos son muy experimentales y, cuándo entra el actor o 
actriz, está muy perdido. Por eso yo le tengo que dar un marco de contención conceptual pero también metodológica. Por ejemplo, si yo le digo a un actor: "experimentemos en el medio de un vagón de subte con gente que no tiene que darse cuenta de que nosotros estamos en medio de una ficción”. Es muy difícil para el actor, entonces intento enmarcarlo en este nuevo territorio que tiene unas reglas específicas.

Las actrices de Distancia, por ejemplo, estaban en sus casas. Algunas de ellas estaban en Europa y hacían la función a las dos de la madrugada mientras estaba sus hijos durmiendo en otras habitaciones... Es un material muy sensible de puertas para adentro del proyecto. Durante las peformances ellas no tenían percepción del público. Sin embargo, tenían preocupaciones técnicas del encuadre o de puesta, o mismo posibles accidentes que evidenciara la presencia de otras personas en la casa.

\section{¿Te parece que hay una relación entre capacidad de subvención y el uso de tecnología en escena? ¿O lo harías aún que no hubiera una subvención?}

La verdad es que es muy difícil hacerlo sin subvención. Distancia es una obra que, claramente, necesitó instituciones para hacerla. Todo lo que piensa el público que es más complicado durante la obra, es lo menos complicado para quienes la hacemos. Por ejemplo, que funcione el streaminges lo menos importante. Lo más importante es un sistema virtual, creado con Rafael Sucheras, que es el compositor musical, y Matía Fabro que es quién me ayudó con toda la parte técnica de sistemas, y fue algo que desarrollamos juntos. Lo complicado fue el sistema virtual que creamos para que le diera pié a las actrices, pero sobretodo a los músicos. Porque no son sólo las actrices que están en sus computadoras en sus casas, sino que hay partituras virtuales para los músicos que están en el escenario. Partituras que son vistas por las actrices, pero también que son escuchadas por los músicos. Hay una computadora que recibe y envía información todo el tiempo, eso lo hace un sistema muy frágil frente a la composición total de la obra. Por eso la siento tan frágil como cualquier obra de teatro con actores en escena. La apuesta sube cuando al final de la obra, el público descubre que una 
de las actrices que pensaba a la distancia está dentro del mismo escenario en una escenografía de un apartamento que permanecía oculta tras algunas de las pantallas.

\section{Que es el departamento de la actriz argentina.}

Sí. Por lo cuál, al final, hay algo del cuerpo y el espacio virtual que cobra otro estado. Es muy fuerte para el público, cuando aparece el cuerpo de una actriz en un estado al que habían renunciado por medio de la virtualidad. Para la actriz argentina, la que está adentro en el escenario, es aún más compleja su relación con lo técnico durante la performance. Al igual que las otras actrices está actuando, está moviendo su computadora; pero ella necesita el apoyo de otros dispositivos electrónicos porque está en medio de una pequeña orquesta de músicos (que se ubican habitando otras partes de la estructura que sostiene las pantallas). Eso genera otro tipo de delay porque la música corre a otra velocidad que la imagen que le llega por la pantalla. Por esto necesita un monitor que le corrija ese delay pero que, sin embargo, también escucha porque los instrumentos están a los lados de las paredes de la escenografía donde ella se esconde. Por otro lado, ella tiene una cámara afuera que le muestra la función tal cuál está sucediendo porque puede cortarse el streaming de otras actrices del exterior, o pueden estar pasando cosas que ella necesita ver desde adentro. Lo mismo pasa con los músicos que tienen que recibir la información de la función como está en términos reales. El argumento para el público está diseñado dramatúrgicamente para que pueda cortarse la conexión en algún caso y que la trama siga su curso.

Por otro lado, creo que Distancia es un viaje emocional para el público. Eso fue una decisión importante para mí porque mi relación con la tecnología no es una relación solemne, a mi la tecnología logró acercarme a territorios muy íntimos y privados respecto a mí y el modo de relacionarme con los otros. Yo pude seguir amando a la distancia, pude sentir a un familiar al lado mío en muchas ocasiones donde estaba muy lejos. Por eso, en mi trabajo, la tecnología no tiene la carga de "acercarnos al futuro" sino al presente. Para mí, la búsqueda central de Distancia 
era acercar al público a la experiencia sensible donde están inmersas las cuatro protagonistas.

Cuando hicimos funciones en Colombia, por ejemplo, se me acercó un investigador diciendo que lo que más le gustaba de la obra era que no volvía solemne el encuentro con lo virtual - como los espectáculos donde se ve un gran despliegue de lo tecnológico - sino que en Distancia lo que más se veía eran personas luchando para habitar la ausencia física o el espacio físico vacío. Por lo que el público se sumerge en un estado emocional de invocación que yo siento como un ritual. Creo que Distancia es un ritual tecnológico, o virtual. Por eso siempre en mi obra como artista está presente la presencia del ritual, porque ese es un posible encuentro con los otros, con la ficción y por ende con nosotros mismos.

\section{Para terminar, cuéntame como es este proyecto que vas a desarrollar con Robert Lepage, de la beca Rolex.}

Cada 4 años, desde el 2002, la marca selecciona 7 comités internacionales que se especializan en distintas disciplinas del arte como la danza, cine, teatro, literatura, música, artes visuales y arquitectura. Cada uno de estos comités lo conforman reconocidas personalidades del sistema cultural que representan las diferentes geografías del mundo y que nominan a los artistas que creen más destacados del panorama global. A partir de eso, como en cualquier premio o distinción, se notifica a cada artista si acepta la nominación y también se le transmite las características del programa Mentors \& Protégé. En esa misma instancia se menciona quién será el mentor que te adjudicarían en el caso de ganar. A partir de eso, si aceptas la nominación, te piden información detallada de cada uno de tus trabajos como artista, notas de prensa, justificaciones conceptuales de cada pieza que fuiste creando, etc. Luego de esa instancia Rolex y sus comités internacionales por disciplina van avanzando en la selección de lo que finalmente serán los 3 finalistas. Cuando llega esa instancia anuncian a los finalistas, les piden que viajen a la 'final' donde se encontrarán con los otros finalistas y también con el que será su mentor. Durante 3 días los finalistas tienen 
una serie de reuniones entre las que se encuentra una reunión privada con su posible mentor. Luego de ese encuentro, cada mentor toma la decisión de quién será su protegido, o discípulo.

Cuando recibí la nominación, fue muy emocionante y realmente me sentí muy identificado con la nominación porque mi mentor es Robert Lepage es un artista interdisciplinario como yo. De hecho, fui nominado por tener una perspectiva interdisciplinaria en mi trabajo como artista. Finalmente llegué a la final y en el pasado mes de junio me anunciaron como uno de los ganadores en el diario New York Times. Con respecto a mi encuentro con Lepage siento que tenemos muchos puntos en común: por un lado, por ser actores, artistas interdisciplinarios y por otro lado por generar colaboraciones globales con nuestro trabajo. Por esta razón estamos juntos en distintos contextos: desde una gira en Japón con uno de sus últimos espectáculos creados con Ex Machina llamado “887", a unos de los espectáculos que montó para el Cirque du Soleil, también viajamos por algunas ciudades de Canadá para investigar asuntos de un nuevo espectáculo que estrenará con la compañía de Ariane Mnouchkine y actualmente estoy en Nueva York acompañando en un montaje en el Metropolitan Opera.

Se trata de encontrarnos en medio de nuestros proyectos, algunos presentes y otros nuevos. Por esta situación cambié mi agenda. Tenía un montón de compromisos de trabajo y bajé los que menos desafíos me significaban en este momento.

Por eso le di lugar a un proyecto que estrené en el diciembre de 2015 en Bogotá llamado dramaHOME y otro proyecto que estrené en agosto de 2016 en el Centro Cultural Recoleta que se llama Construcciones. En ambos casos se tratan de piezas virtuales: Construcciones es una instalación de video y dramaHOME es una performance site specific. En el caso de dramaHOME siento que es una síntesis de algunos trabajos porque aparece la figura de las amas de casa, la dramaturgia y la tecnología. 


\section{¿No son actrices?}

No. Son siete mujeres que dejaron sus trabajos para dedicarse al hogar como amas de casa, que también deberíamos reconocerlo como un trabajo, y pertenecen a distintos sistemas sociales que conviven como diferentes realidades sociales. Yo trabajé durante algunas semanas con ellas abriendo el canal de la escritura y permitiendo que esa nueva dimensión expresiva abra nuevas formas de la percepción del presente en referencia a lo amoroso, a lo social, a lo político y económico. En términos concretos se trata de una performance que ellas realizan desde sus propias casas, es decir en el espacio urbano de 7 viviendas del barrio de Teusaquillo en Bogotá. En cada caso les fue entregado una computadora donde ellas debían escribir durante 7 días, las 24 horas, todo a aquello que piensan, que sienten, que anhelan, que sueñan reflexiones sobre la realidad sin los prejuicios de la realidad, casi componiendo un diario de pensamientos digitados como dramaturgas de sus propios hogares. La particularidad es que esas computadoras están conectadas a pantallas de LED que se ubican en las fachadas de sus casas. Esos carteles transmiten todo aquello que escribe cada una de las mujeres desde el interior de su casa en carteles que simulan el subtitulado de una película. Por lo que con esta obra el paisaje urbano cambia y existen dos tipos de espectadores: los que se acercan a la institución que programó dramaHOME y allí obtienen un mapa para ver la experiencia y descubrir las distintas dramaturgias urbanas que expulsan las casas, y otros espectadores emancipados que son los ciudadanos que se encuentran con los carteles electrónicos sorpresivamente en el caminar cotidiano... Esta acción desconfigura su presente y extraña la realidad cambiando el paisaje urbano provocando otro tipo de pensamientos a partir de textos que leen en las fachadas de esas casas como: "Ya no amo a mi marido", "si fuera un homeless yo también me drogaría". Porque lo interesante es como esas mujeres, por medio de herramientas de narrativas, empiezan a jugar en un cotidiano dónde la dramaturgia permite ficcionalizar sus vidas.

En el caso de Construcciones se trata de una video instalación presentada en una de las salas del Centro Cultural Recoleta con acceso al público durante tres 
meses en un amplio espectro horario al igual que en un museo. La principal pregunta que me hago en este proyecto es ¿cómo se constituye un mito en el presente? Una pregunta que vengo trabajando desde TeatroSOLO pero aquí desde otra perspectiva. En el proyecto Construcciones parto de este interrogante y me vuelvo a tomar de la oralidad y la mediación artística para profanar la entidad anónima del mito y la ilusión de verdad de lo documental. Sobre todo, porque el mito no habla de vos, ni de mí, sino de nosotros. Entonces... individuos cuyo trayecto supera los 75 años y que han vivido una o varias vidas, son creadores y personajes de su narración sobre los hechos prodigiosos o funestos de la historia del país que habitan. Tras las tesis etnológicas que afirman que "todas las versiones del mito son verdaderas" existe un primer relato-retrato experiencial en la voz de su protagonista - que permanecerá a resguardo en la web del proyecto. Esta versión virtual, que se trata de una entrevista donde los distintos protagonistas hablan de sus vidas, el espectador puede escuchar esa primera voz, esa primera idea del mito, e inclusive puede escribir sus impresiones frente a la experiencia. La segunda etapa del proyecto es justamente la video instalación que fue instalada en el salón del Centro Cultural Recoleta. Allí los espectadores/as ingresaban en una sala oscura donde solamente se desprendían 9 figuras virtuales de cada uno de los protagonistas de cada historia. Estas 9 figuras son 9 video retratos que se emiten en 9 televisores de LED de gran tamaño. Al encontrarse cada espectador frente a cada video retrato, puede tomar unos auriculares y una voz relata la vida de esa persona que está viendo (tomándose para construir dicho relato la primera entrevista que se encuentra online en la página del proyecto). En esta segunda etapa se construye el mito desde una segunda voz que no es la del protagonista, sino la del artista que narrativamente envuelve al espectador en la vida de esa persona. Finalmente, Construcciones genera una oralidad desplegada por acumulación de voces porque la tercera versión del mito, o tercera etapa del proyecto, es cuando el público sale de la sala de la video instalación, y transmite a sus conocidos aquellos relatos que escuchó sobre la vida de otras personas, al igual que los mitos que algunas veces hemos escuchado. 
Muchas gracias por la entrevista, fue un placer charlar contigo.

Buenos Aires, 12 de Julio de 2016. Café Recoleta.

Matías Umpierrez ${ }^{4}$

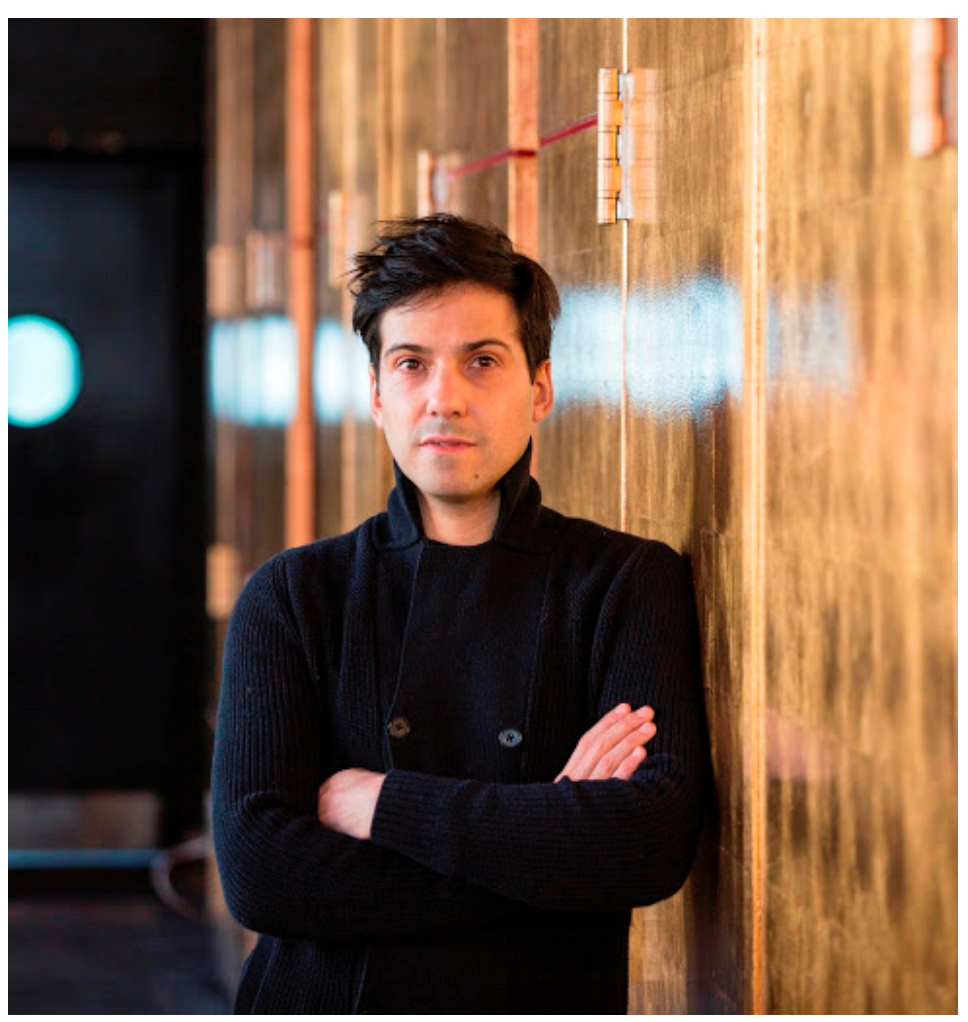

Recebido em: 12/04/2020

Aprovado em: 17/05/2020

Universidade do Estado de Santa Catarina - UDESC

Programa de Pós-Graduação em Teatro - PPGT

Centro de Arte - CEART

Urdimento - Revista de Estudos em Artes Cênicas

urdimento.ceart@udesc.br

4 Fonte: http://elgranotro.com/iniciativa-artistica-rolex/matias-umpierrez-finalist-in-theatre-photographedat-la-caserne-quebec-2/ 